being well represented by the names of Heaviside, Kelvin, Preece and S. P. Thompson, all of whom were honorary members of the American Institute. The publication is a very fitting tribute to the pioneers whose work is so admirably appraised by C. F. Scott, a former president of the Institute, in the following words: "In the fabric of electrical engineering the long scientific threads of the warp are bound together and given pattern and utility by cross threads which are the life achievements of individuals. As the loom keeps weaving through the years new threads of scientific knowledge are added to the old, and new workers contributing woof of finer quality enrich the beauty and enhance the utility of the product."

\section{Drought of 1934 in the United States}

"BY the close of May 1934 the most extensive drought in the climatological history of the United States had developed in the central valleys, the Lake Region and the North-western and Western States," states J. B. Kincer, Chief of the Climate and Crop Weather Division of the U.S. Weather Bureau, in the Scientific Monthly of July, p. 95. In North Dakota the three spring months (March-May) yielded only $1.25 \mathrm{in}$. of rain, against the previous low record of $2 \cdot 15 \mathrm{in}$. in 1901 . In the north-west the serious shortage in sub-soil moisture and surface water supplies is the result of an accumulated deficiency covering several years. There is no reason to suppose, however, that this prolonged deficiency indicates a permanent drift towards desert-like conditions; for long-period records show that periods of excessive drought may be expected to occur at intervals of $30-40$ years. Thus similar periods of years with markedly deficient rainfall covered the ten years ending with 1864 and again the ten years ending with 1894, while between these periods were successive years with comparatively abundant rains. The 1934 drought was unusual in developing early, and as a consequence, instead of the corn crops being most seriously affected as occurs in summer droughts, the crops which have suffered most so far are hay, pastures and small grains.

\section{Meteorology in Southern Rhodesia}

According to the meteorological report of the Department of Agriculture, Southern Rhodesia, for the year ended June 30, 1933, there was comparatively little change, up to October 1, 1933, in the number of observing stations representing that country, thirty-six new stations having been opened and twenty former stations altered or closed, the total number on that date standing at 601 , of which all but fifty are rainfall stations. The seasonal rainfall was below the normal, as was that of the three preceding seasons with the exception of 1931-32, the deficit being nearly 4 inches. For the fourth year in succession, the seasonal rainfall was forecast with the aid of a formula based on the values of meteorological data at distant 'centres of action', and the sign of the departure from the average was successfully predicted again as at the three earlier attempts-a very praiseworthy result. The report in its general lines follows those of the earlier years. Monthly means of barometric pressure, of temperature and of relative humidity for each of the twenty-four hours are given for Salisbury and Bulawayo, and monthly sunshine totals for the day light hours ; the distribution of rainfall for the whole period is shown cartographically in colours, and there are many climatic summaries on standard lines. There are also summaries of the upper winds measured with the aid of pilot balloons, and of the records of pressure tube anemometers situated at Salisbury and Bulawayo. Dines pressure-tube anemometers have been erected during the year at Fort Victoria, Que Que and Miami. Very satisfactory progress in the collection of comparable climatic data for this country is revealed by this well-arranged and clearly printed report.

\section{The Periodic Law}

THE Mendeleefi Centenary Lecture was delivered before the Chemical Society at the Royal Institution on April 19 by Lord Rutherford, and is printed in the Journal of the Society for May. Lord Rutherford gave an account of the researches on atomic structure which have led to a realisation of the true meaning of the Periodic Law (see Nature, 133, 161, 656; 1934), with so many of which he has himself been associated. He dealt with the question of the order of the elements, as defined by the atomic number, with the discovery of isotopes, with the arrangement of electrons outside the atom, and with a number of related topics. The lecture sets out very clearly the course of investigation which has provided an explanation of the remarkable generalisation proposed by Mendeleeff in 1869 , and also the elucidation of some points of difficulty associated with the Periodic Table before the work of Moseley in 1912-13, which Lord Rutherford described as "an outstanding landmark in the history of our knowledge of the elements".

\section{The Zoological Park of Paris}

MANY initial difficulties having been overcome, Paris has now a zoological park worthy of the nation, constructed in the Bois de Vincennes upon ground reserved by a law of 1860 . The Parc zoologique du Bois de Vincennes, recently inaugurated by the President of the Republic, covers a triangle of about 14 hectares, the longest side bordering Lake Daumesnil. At one of the main entrances rises a hill 68 metres high, on top of which a group of picturesque rocks ingeniously masks two great reservoirs containing the water necessary for the animals. The general idea has been to avoid the stilted cramped zoological garden of the past and to exhibit the animals in open and appropriate spaces, as if in a state of semi-liberty. The photographs illustrating Jean de la Cerisaie's article in La Nature of July 1, p. 30, show that the idea has been carried out with skill and artistry. The Zoological Park of Vincennes with its 1,500 animal inmates takes its place worthily with the other modern zoos of Europe. 